\title{
BMJ Open Effect of epidural analgesia on cancer prognosis after colon cancer resection: a single-centre cohort study in Taiwan
}

\author{
Hsiang-Ling Wu, ${ }^{1,2}$ Ying-Hsuan Tai, ${ }^{3,4}$ Mercedes Susan Mandell, ${ }^{5}$ Mei-Yung Tsou, ${ }^{1,2}$ \\ Shung-Haur Yang, ${ }^{2,6,7}$ Tony Hsiu-Hsi Chen (D) , ${ }^{8}$ Kuang-Yi Chang (D) ${ }^{1,2}$
}

To cite: Wu H-L, Tai Y-H, Mandell MS, et al. Effect of epidural analgesia on cancer prognosis after colon cancer resection: a single-centre cohort study in Taiwan. BMJ Open 2020;10:e036577. doi:10.1136/ bmjopen-2019-036577

- Prepublication history and additional material for this paper are available online. To view these files, please visit the journal online (http://dx.doi. org/10.1136/bmjopen-2019036577).

Received 20 December 2019 Revised 26 August 2020 Accepted 21 September 2020

Check for updates

(c) Author(s) (or their employer(s)) 2020. Re-use permitted under CC BY-NC. No commercial re-use. See rights and permissions. Published by BMJ.

For numbered affiliations see end of article.

Correspondence to

Dr Kuang-Yi Chang;

kychang@vghtpe.gov.tw

\section{ABSTRACT}

Objectives Whether epidural analgesia affects cancer outcomes remains controversial. Most previous investigations ignored the confounding potential of important pathological factors on cancer outcomes. This study aimed to assess the association between epidural analgesia and cancer recurrence or death after resections for colon cancer.

Design Retrospective cohort study.

Setting A single-medical centre in Taiwan.

Participants Patients with stage I through III colon cancer undergoing bowel resection and receiving either epidural analgesia or intravenous opioid analgesia from 2005 to 2014.

Primary and secondary outcome measures Primary outcome was postoperative recurrence-free survival and secondary outcome was overall survival.

Results A total of 2748 and 1218 patients were analysed before and after propensity score matching. Cox regression analyses did not demonstrate any association between epidural analgesia and recurrence or death after matching (HR 0.89, 95\% Cl 0.65 to 1.21 for recurrence; 0.72, 95\% $\mathrm{Cl} 0.48$ to 1.09 for death). Independent prognostic factors for cancer recurrence and death were higher level of preoperative carcinoembryonic antigen, perioperative blood transfusion, advanced cancer stage and pathological lymphovascular invasion.

Conclusions No definite association was found between epidural analgesia and risk of recurrence or death in patients undergoing colon cancer resection.

\section{INTRODUCTION}

In 2018, approximately 1850000 new cases of colorectal cancer were diagnosed worldwide, and 881000 died of colorectal cancer. ${ }^{1}$ Colorectal cancer is ranked as the second most common cause of cancer death and poses a significant economic and healthcare burden globally. ${ }^{1}$ For localised colorectal cancer, surgical removal of primary tumour is the only curative treatment modality, but about one-third of patients with stage II and III diseases developed cancer recurrence after resection surgery, which significantly reduced their long-term survival. ${ }^{2}$

\section{Strengths and limitations of this study}

A large cohort with long follow-up time was used to improve statistical power for the evaluation of epidural effects on long-term outcomes after colon cancer resection.

- Important pathological prognostic factors were considered in the analysis to reduce potential confounding effects.

- Propensity score matching methodology was employed to correct imbalances in the collected variables.

- Effects of unrecorded confounders on colon cancer outcomes cannot be further evaluated.

- The generalisability of study results may be limited due to the single medical centre design.

Epidural analgesia (EA) has been commonly used for controlling acute pain during and after abdominal surgery. The decrease in the stress response by EA may ameliorate surgery-related immunosuppression and thereby protect patients from postoperative tumour metastases. ${ }^{3}{ }^{4}$ Furthermore, opioids suppress both cellular and humoral immunity in humans, ${ }^{56}$ and EA may help preserve immune function and protect against tumour spread by reducing perioperative use of opioids. However, whether EA reduces cancer recurrence or mortality in colorectal cancer remains inconclusive, with benefits reported in some studies ${ }^{7-12}$ but not in others. ${ }^{13-15}$ Prior studies had limitations of small patient sample $(<500$ subjects using epidurals) ${ }^{7811-15}$ surgery performed before $2005,{ }^{7-1315}$ and mixed groups of subjects for different cancer pathology. ${ }^{791213}$ Pathological features of specimen are the major prognostic determinants after curative-intent surgery in colorectal cancer. $^{16}$ Nevertheless, previous studies did not take a complete consideration of these critical pathological predictors and ignored their potentially confounding effects on cancer prognosis. ${ }^{791213}$ 
Accordingly, we performed this study to examine the impact of EA on oncological outcomes after colon cancer resection with a particular emphasis on the adjustment for major prognostic factors by a comprehensive review of pathology reports. Specifically, we tested the hypothesis that EA was linked to longer recurrence-free survival (RFS) and overall survival (OS) in patients with stage I through III colon cancer after primary tumour resection.

\section{METHODS}

The electronic medical databank was used to identify patients undergoing tumour resection for histologically proven colorectal cancer at the medical centre between 2005 and 2014. Exclusion criteria were patients with missing data about clinical and pathological factors, nonadenocarcinoma, distant metastasis at the time of surgery, pathology-proven carcinoma in situ and follow-up time less than 30 days. Due to the obvious difference in cancer treatment strategies and short-term prognosis between colon cancer and rectal cancer, ${ }^{17}$ we also excluded rectal cancer to increase the sample homogeneity (figure 1).

A total of 2748 patients were eligible for propensity score matching after meeting the selection criteria. Patients were classified into two groups: patients undergoing general anaesthesia with EA or without EA. The dataset of all the included patients was collected by a specialist anaesthesiologist. Specialist gastroenterologists were consulted when staging of cancer or time of recurrence was unclear in the medical records.

\section{Analgesic management}

EA has been an integral part of postoperative pain control at this centre since 1990. Epidural catheter was typically placed at T10-T12 spine and tested before surgery. EA was given with a loading dose of lidocaine 60-100 mg before surgical incision and a basal infusion of bupivacaine $0.25 \%$ or $0.5 \%$ with or without fentanyl $1-2 \mu \mathrm{g} / \mathrm{mL}$ at a rate of $5-10 \mathrm{~mL} /$ hour. EA was typically continued for 48-72 hours for controlling postoperative pain. However, some patients undergoing bowel resection did not receive EA for the presence of contraindications to epidurals, ineffective epidurals or preference of patients or surgeons. Patients without epidurals would receive intravenous patient-controlled or as-needed opioid-based analgesia at the discretion of patients and anaesthesiologists. ${ }^{18}$

\section{Clinicopathological characteristics}

The baseline attributes and potential predictor variables for cancer recurrence and mortality were derived from the medical record system as reported in our prior articles. ${ }^{19-22}$ Clinical variables included demographics, pretreatment carcinoembryonic antigen (CEA) concentration, ${ }^{23}$ perioperative use of packed red blood cells ${ }^{202425}$ and the use of preoperative or postoperative adjuvant chemotherapy or radiation therapy. Perioperative red cell transfusion was defined as any red cells given during

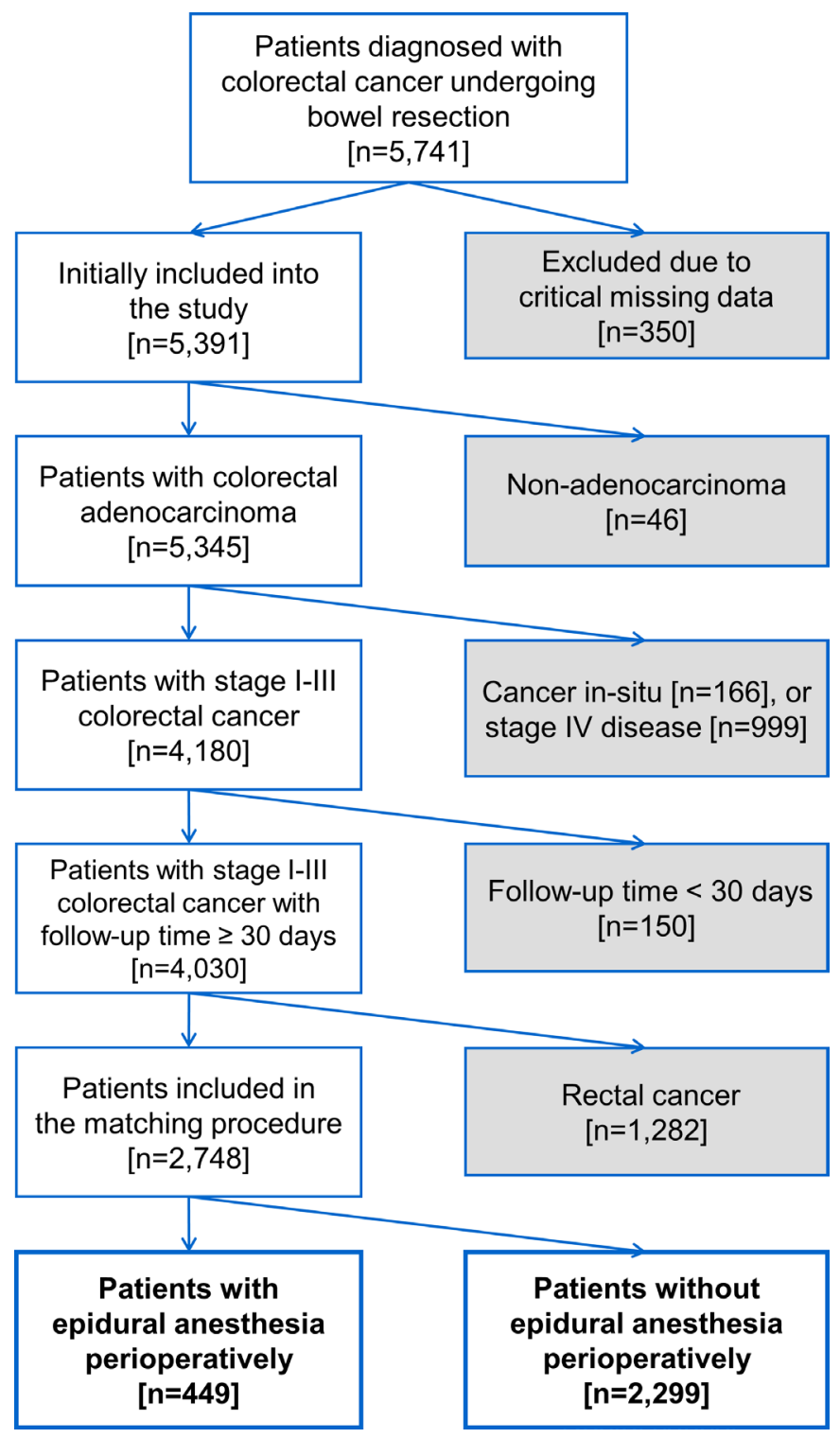

Figure 1 Flow diagram for patient selection.

or within 7 days after surgery. Adjuvant chemotherapy (leucovori and oxaliplatin or 5-fluorouracil; capecitabine; tegafur-uracil) or radiotherapy was defined as any treatment given within 90 days before or after surgery.

Pathological covariates comprised cell differentiation, ${ }^{16}$ mucinous or signet-ring histology, ${ }^{26}$ lymphovascular inva$\operatorname{sion}^{27}$ and perineural invasion. ${ }^{28}$ Tumour nodes metastasis (TNM) staging was translated into stages I-III according to the American Joint Committee on Cancer (AJCG) criteria, seventh edition. ${ }^{29}$ Tumour location was divided into right-sided tumour (cecum to splenic flexure), leftsided tumour (splenic flexure to sigmoid colon). ${ }^{30}$

\section{Outcome measurement}

Primary outcome is RFS, defined as time from the date of surgery to the date of first cancer recurrence. Recurrence was determined by the presence of locoregional or metastatic lesions on imaging (plain radiography, spiral CT or MRI). Secondary outcome is OS, defined as time 
from the date of surgery to the date of mortality. Each patient's status was determined by the medical record of outpatient surveillance or subsequent admissions. Datasets were updated until 31 August 2016. For those without recurrence or death, survival times were considered as the corresponding censored observations.

\section{Statistical analysis}

Comparisons of baseline attributes between epidural and non-epidural groups were performed using $\chi^{2}$ tests for categorical covariates and either t-tests or Wilcoxon rank-sum tests for continuous covariates, as appropriate. Kaplan-Meier method was applied to compare the RFS and OS curves between groups. Univariate Cox regression analysis was used to assess the effect of covariates on recurrence-free or OS. Significant variables of recurrence-free or OS in univariate analysis were considered as candidates for stepwise model selection procedures in multivariable models. The association between EA and outcomes was further examined by adjusting for the determined predictors of the multivariable models.

To cope with the potential imbalance of measured confounders between two groups, propensity scores based on a list of patient characteristics was generated to estimate the probability of receiving epidurals ${ }^{31}$ (online supplemental table 1 ). Propensity score analysis with 1:2 matching was conducted as the primary analysis to ensure sufficient balance in collected variables among matching groups. Stratified Cox regression analysis by matching groups was applied to examine the association between EA and cancer recurrence or OS. The significance level for all hypotheses was 0.05 for a two-tailed test. All the statistical analyses were performed using IBM SPSS Statistics, V.23.0 (IBM).

\section{Patient and public involvement}

This study is a retrospective analysis using the institutional medical database. There was no patient involved in the recruitment to and conduct of the study.

\section{RESULTS}

Among the included 2748 patients, 449 (16.3\%) used EA. Median follow-up interval was 46.1 months (IQR 25.0-72.6). Note that patients receiving EA had longer follow-up interval and were more likely to have open surgery before matching (table 1). The proportion of epidural use decreased due to increasing use of laparoscopic technique for colon cancer resection at this centre in recent years. Online supplemental figure 1 shows the rate of epidural use in colon cancer resection significantly decreased from 2011 onwards. No significant difference in the cancer stage or pathological features was noted between groups (table 2). After propensity score matching, the final sample of 406 matched groups was analysed (tables 1 and 2).

\section{EA and recurrence risk}

Before matching, the 3 years and 5 years RFS rates were $84.4 \%$ (95\% CI $80.9 \%$ to $87.9 \%$ ) and $80.9 \%$ (95\%
CI $77.0 \%$ to $84.8 \%$ ) in EA group and $82.2 \%$ (95\% CI $80.4 \%$ to $84.0 \%$ ) and $79.0 \%$ (95\% CI $77.0 \%$ to $81.0 \%$ ) in non-EA group, respectively. Note that EA was not associated with recurrence risk in the univariate analysis (HR $0.85, \mathrm{p}=0.183$ ) (figure 2A).

Multivariable analysis identified eight independent prognostic factors of cancer recurrence, including preoperative CEA level (on base-10 logarithmic scale, $\mathrm{HR}=2.01$ ), longer anaesthesia time (on base-2 logarithmic scale, $\mathrm{HR}=1.31$ ), cancer stage (II vs $\mathrm{I}, \mathrm{HR}=6.41$; III vs $\mathrm{I}, \mathrm{HR}=14.6$ ), perioperative red cell transfusion $(\mathrm{HR}=1.48)$, signet-ring histology $(\mathrm{HR}=1.71)$, pathological lymphovascular invasion $(\mathrm{HR}=1.28)$, perineural invasion $(\mathrm{HR}=1.81)$ and preoperative chemotherapy and/or radiotherapy $(\mathrm{HR}=3.02)$. (table 3$)$ The effect of EA on RFS after colon cancer surgery remained non-significant after the adjustment for these independent predictors (HR $0.85,95 \%$ CI 0.65 to 1.10 ). After matching, stratified Cox regression model shows non-significant difference in the risk of cancer recurrence between groups (HR 0.89, $95 \%$ CI 0.65 to $1.21 ; p=0.449$ ). There was no significant association between EA and RFS in different subgroups of cancer stage (online supplemental table 2).

\section{EA and mortality risk}

The 3 years and 5 years OS rates were $92.5 \%$ (95\% CI $90.0 \%$ to $95.0 \%$ ) and $87.2 \%$ (95\% CI $83.7 \%$ to $90.7 \%$ ) in EA group and $92.4 \%$ (95\% CI $91.2 \%$ to $93.6 \%$ ) and $87.9 \%$ ( $95 \%$ CI $86.1 \%$ to $89.7 \%$ ) in non-EA group, respectively. No significant difference in postoperative OS was noted between groups $(\mathrm{p}=0.277$ by log rank test, figure 2B). In the univariate analysis, EA was not associated with mortality risk $(\mathrm{HR}=0.85, \mathrm{p}=0.278)$. Multivariable model identified 11 independent prognostic factors of OS, including older age ( $\mathrm{HR}=1.03)$, male $(\mathrm{HR}=1.30)$, ASA class $\geq 3 \quad(\mathrm{HR}=1.82)$, heart failure $(\mathrm{HR}=1.60)$, chronic kidney disease $(\mathrm{HR}=1.44)$, preoperative CEA concentration (on base-10 logarithmic scale, $\mathrm{HR}=1.44$ ), cancer stage (II vs I, HR=1.19; III vs I, HR=1.81), perioperative $\mathrm{pRBC}$ transfusion $(\mathrm{HR}=1.92)$, pathological lymphovascular invasion ( $\mathrm{HR}=1.49)$, mucinous histology $(\mathrm{HR}=1.93)$ and radiotherapy $(\mathrm{HR}=2.67)$ (table 4$)$. The effect of EA on OS after colon cancer surgery remained non-significant after the adjustment for these significant predictors ( $\mathrm{HR}=0.76,95 \%$ CI 0.56 to 1.03$)$, similar to the results of stratified Cox regression model (HR $=0.72,95 \%$ CI 0.48 to $1.09 ; \mathrm{p}=0.119$ ) after matching. Subgroup analyses showed EA was not associated with the risk of all-cause mortality in distinct cancer stages (online supplemental table 2).

\section{DISCUSSION}

We found no definite evidence that EA was linked to better RFS or OS in colon cancer after primary tumour resection. Our study provided valuable evidence to challenge the association between EA and cancer outcomes with two strengths. First, our analysis was based on a large cohort to increase the statistical power and obtained 


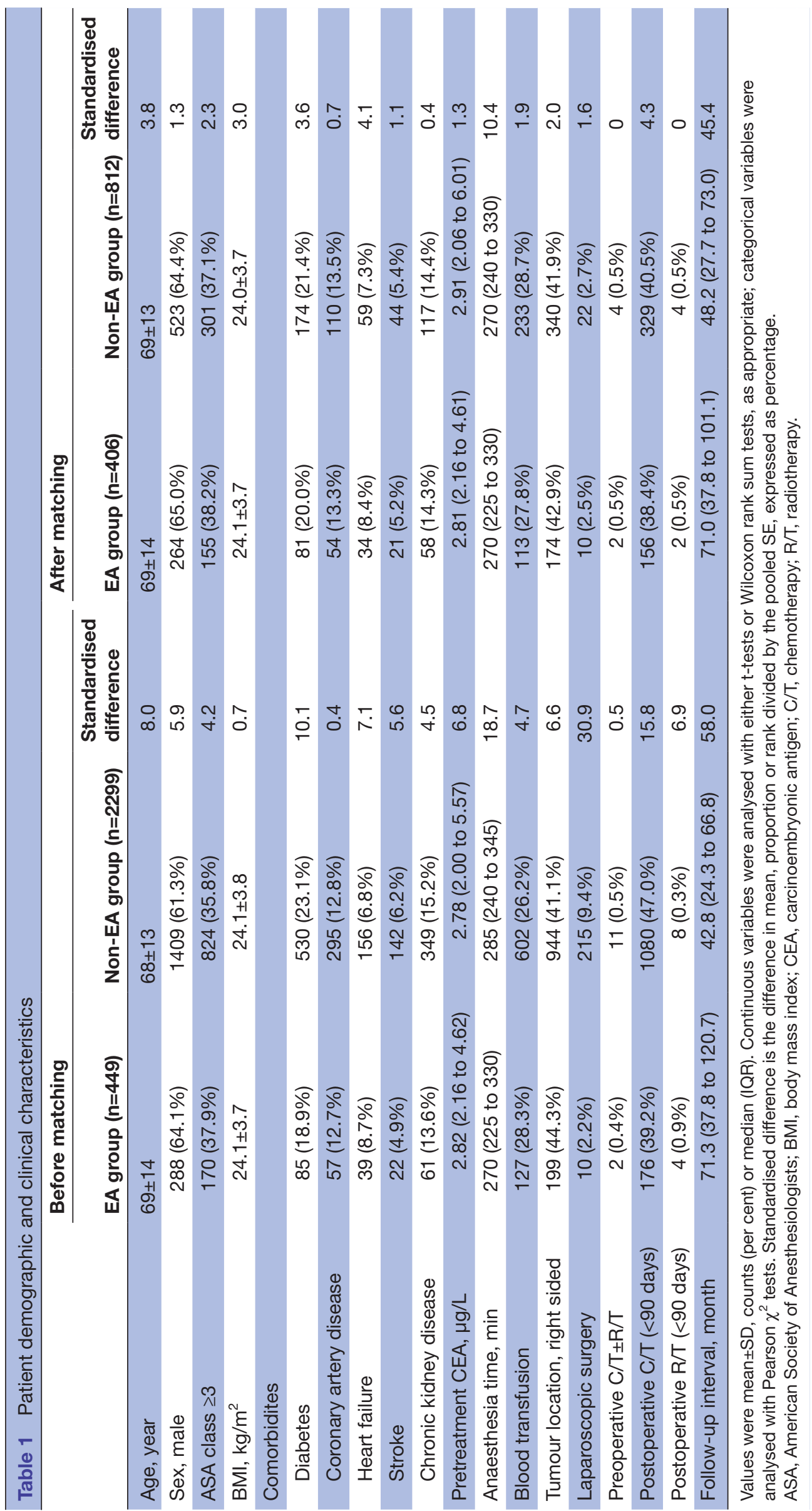


Table 2 Cancer staging and pathological features

\begin{tabular}{|c|c|c|c|c|c|c|}
\hline & \multicolumn{3}{|c|}{ Before matching } & \multicolumn{3}{|c|}{ After matching } \\
\hline & $\begin{array}{l}\text { EA group } \\
(n=449)\end{array}$ & $\begin{array}{l}\text { Non-EA group } \\
(n=2299)\end{array}$ & $\begin{array}{l}\text { Standardised } \\
\text { difference }\end{array}$ & $\begin{array}{l}\text { EA group } \\
(n=406)\end{array}$ & $\begin{array}{l}\text { Non-EA group } \\
(n=812)\end{array}$ & $\begin{array}{l}\text { Standardised } \\
\text { difference }\end{array}$ \\
\hline Stage I & $97(21.6 \%)$ & $500(21.7 \%)$ & & $91(22.4 \%)$ & $175(21.6 \%)$ & \\
\hline Stage II & $190(42.3 \%)$ & 977 (42.5\%) & & $175(43.1 \%)$ & $374(46.1 \%)$ & \\
\hline IIC & $3(0.7 \%)$ & $24(1.0 \%)$ & & $3(0.7 \%)$ & $12(1.5 \%)$ & \\
\hline Stage III & $162(36.1 \%)$ & $822(35.8 \%)$ & & $140(34.5 \%)$ & $263(32.4 \%)$ & \\
\hline IIIA & $5(1.1 \%)$ & $63(2.7 \%)$ & & $4(1.0 \%)$ & $19(2.3 \%)$ & \\
\hline IIIB & $128(28.5 \%)$ & $591(25.7 \%)$ & & $109(26.8 \%)$ & $196(24.1 \%)$ & \\
\hline Good & $36(8.1 \%)$ & $174(7.6 \%)$ & & $33(8.1 \%)$ & $64(7.9 \%)$ & \\
\hline Moderate & $379(84.8 \%)$ & $1958(85.7 \%)$ & & $345(85.0 \%)$ & 701 (86.3\%) & \\
\hline Poor & $32(7.2 \%)$ & $153(6.7 \%)$ & & $28(6.9 \%)$ & $47(5.8 \%)$ & \\
\hline Mucinous histology & $22(4.9 \%)$ & 97 (4.3\%) & 3.2 & $18(4.4 \%)$ & $35(4.3 \%)$ & 0.6 \\
\hline Signet-ring histology & $15(3.4 \%)$ & $61(2.7 \%)$ & 4.1 & $13(3.2 \%)$ & $20(2.5 \%)$ & 4.5 \\
\hline Lymphovascular invasion & $57(12.8 \%)$ & 455 (19.9\%) & 19.5 & $50(12.3 \%)$ & $113(13.9 \%)$ & 4.7 \\
\hline Perineural invasion & 17 (3.8\%) & 192 (8.4\%) & 19.3 & 15 (3.7\%) & 15 (1.8\%) & 11.3 \\
\hline
\end{tabular}

Values were counts (per cent). Categorical variables are analysed with Pearson $\chi^{2}$ tests.Standardised difference is the difference in mean, proportion or rank divided by the pooled SE, expressed as percentage.

AJCC, American Joint Committee on Cancer; EA, epidural analgesia.

more reliable results. Second, propensity score matching method based on a comprehensive collection of predictors was applied to minimise potential confounding effects and selection bias.

Retrospective studies reported that EA was associated with longer OS in patients with non-metastatic colorectal cancer. $^{71012}$ Other studies suggested benefits of EA to survival in specific populations (patients with rectal cancer

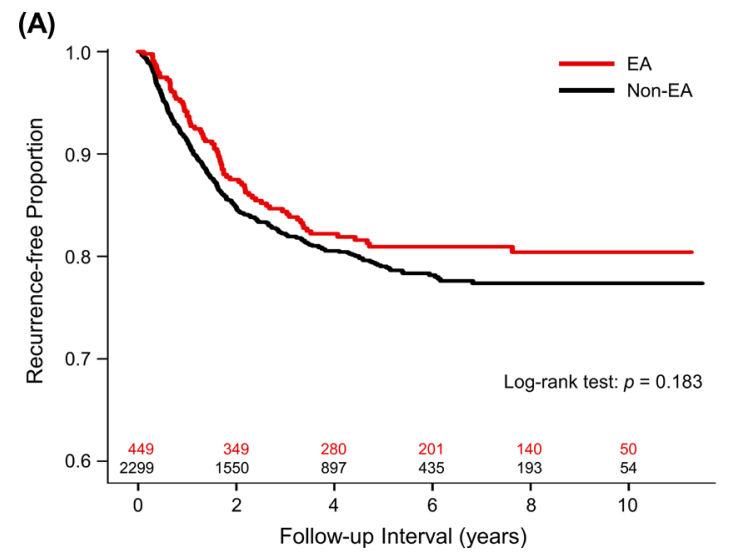

or ASA class three or 4). ${ }^{911}$ So far, available literature refuted reduction in cancer recurrence after colorectal cancer surgery with EA. ${ }^{81013-15}$ The observed difference in OS may be potentially confounded by unmeasured predictors and our study fills this gap by incorporating more explanatory variables into the analysis. In a retrospective analysis, Warschkow et al reported that EA was associated with a reduced risk of postoperative pneumonia

(B)

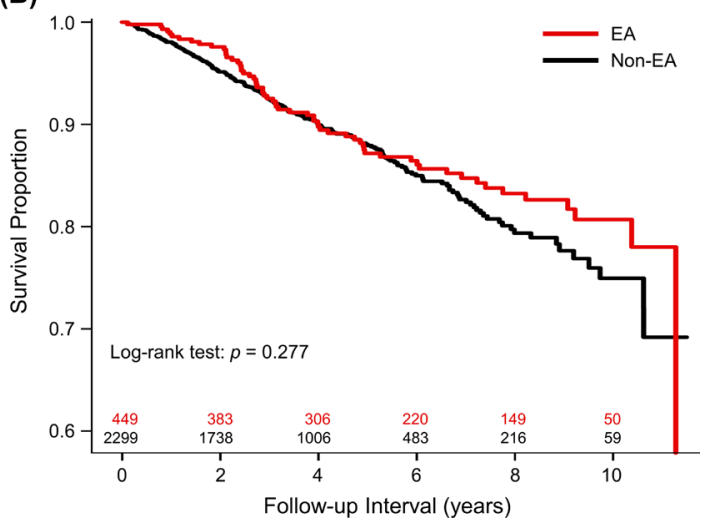

Figure 2 Kaplan-Meier curves for cancer recurrence and all-cause mortality of EA and non-EA groups with number of subjects at risk. No significant difference in cancer recurrence or all-cause mortality after colon cancer resection was found when comparing EA with non-EA groups. EA, epidural analgesia. 


\begin{tabular}{|c|c|c|c|}
\hline & HR & $95 \% \mathrm{Cl}$ & $P$ value \\
\hline Epidural analgesia & 0.85 & 0.65 to 1.10 & 0.210 \\
\hline Pretreatment CEA* & 2.01 & 1.71 to 2.36 & $<0.001$ \\
\hline Anaesthesia time $†$ & 1.31 & 1.04 to 1.66 & 0.023 \\
\hline Blood transfusion & 1.48 & 1.22 to 1.80 & $<0.001$ \\
\hline AJCC stage & & & $<0.001$ \\
\hline II vs I & 6.41 & 3.26 to 12.61 & $<0.001$ \\
\hline III vs I & 14.64 & 7.48 to 28.66 & $<0.001$ \\
\hline Lymphovascular invasion & 1.28 & 1.02 to 1.60 & 0.030 \\
\hline Perineural invasion & 1.81 & 1.38 to 2.36 & $<0.001$ \\
\hline Signet-ring histology & 1.71 & 1.15 to 2.55 & 0.008 \\
\hline Preoperative $\mathrm{C} / \mathrm{T} \pm \mathrm{R} / \mathrm{T}$ & 3.02 & 1.24 to 7.34 & 0.015 \\
\hline
\end{tabular}

*On base-10 logarithmic scale.

†On base-2 logarithmic scale.

AJCC, American Joint Committee on Cancer; CEA,

carcinoembryonic antigen; $\mathrm{C} / \mathrm{T}$, chemotherapy; $\mathrm{R} / \mathrm{T}$, radiotherapy.

in patients undergoing open colorectal cancer surgery, but mortality rate was similar between epidural and nonepidural groups. ${ }^{32}$ Meta-analysis has demonstrated that regional anaesthesia may protect against development of postoperative pulmonary complications in patients with chronic respiratory diseases. ${ }^{33}$ Similarly, a multicentre randomised controlled trial recently reported that regional anaesthesia and analgesia using paravertebral block reduced the risk of postoperative pulmonary

Table 4 Forward model selection for overall survival before matching

\begin{tabular}{llll}
\hline & HR & $\mathbf{9 5 \%}$ Cl & P value \\
\hline Epidural analgesia & 0.76 & 0.56 to 1.03 & 0.075 \\
\hline Age & 1.03 & 1.02 to 1.04 & $<0.001$ \\
Sex (M vs F) & 1.30 & 1.00 to 1.68 & 0.050 \\
\hline ASA class $\geq 3$ & 1.82 & 1.38 to 2.40 & $<0.001$ \\
\hline Heart failure & 1.60 & 1.14 to 2.25 & 0.007 \\
\hline Chronic kidney disease & 1.44 & 1.09 to 1.89 & 0.010 \\
\hline Pretreatment CEA* & 1.44 & 1.13 to 1.83 & 0.003 \\
\hline Blood transfusion & 1.92 & 1.49 to 2.48 & $<0.001$ \\
\hline AJCC Stage & & & 0.001 \\
\hline II vs I & 1.19 & 0.80 to 1.77 & 0.379 \\
\hline III vs I & 1.81 & 1.22 to 2.70 & 0.003 \\
\hline Lymphovascular invasion & 1.49 & 1.12 to 1.98 & 0.006 \\
\hline Mucinous histology & 1.93 & 1.25 to 2.99 & 0.003 \\
\hline Postoperative R/T & 2.67 & 1.08 to 6.64 & 0.034 \\
\hline
\end{tabular}

${ }^{*}$ On base-10 logarithmic scale

AJCC, American Joint Committee on Cancer; ASA, American

Society of Anesthesiologists; CEA, carcinoembryonic antigen; C/T, chemotherapy; F, female; $\mathrm{M}$, male; $\mathrm{R} / \mathrm{T}$, radiotherapy. complications but not recurrence or mortality in breast cancer after curative surgery compared with systemic opioid therapy. ${ }^{34}$

In addition to clinical features, pathological examination of the resected specimen is the most powerful tool for predicting prognosis after curative-intent surgery of colorectal cancer. ${ }^{16}$ Previous reports were only adjusted for TNM or AJCC stages and tumour differentiation at most. ${ }^{7-1315}$ In fact, microscopic lymphovascular and perineural invasion have been proved to be important predictors of cancer recurrence and all-cause mortality in colorectal cancer. ${ }^{1627} 28$ In our analysis, microscopic lymphovascular invasion independently increased risk of cancer recurrence and all-cause mortality. Moreover, AJCC has recommended including pretreatment serum CEA levels (C stage) into the conventional TNM staging system of colorectal cancer. ${ }^{23}$ Our study also demonstrated pretreatment CEA level as an independent predictor for colon cancer recurrence and support routine preoperative CEA testing on diagnosis of colon cancer.

Attention to some limitations of this study is needed. First, the effects of unrecorded confounders cannot be further evaluated, including use of opioids, conversion from laparoscopic to open surgery, surgical margin, genetic mutations of tumour, types and cycles of chemotherapy, and additional treatments for subsequently developed recurrence. Notably, our previous study showed no definite association between morphine consumption within 72 hours after surgery and long-term cancer outcome in patients with colorectal cancer using intravenous patient-controlled analgesia. ${ }^{35}$ Second, the procedure of propensity score matching resulted in a loss of patient sample and statistical power. Third, the follow-up time for patients treated with EA was significantly longer than for patients without $\mathrm{EA}$, which may possibly lead to outcome assessment bias. Nevertheless, the chance of colon cancer recurrence is greatest within 5 years after surgical resection. ${ }^{36}$ In our study, patients followed up for more than 6 years in the non-EA group was obviously outnumbered those in the EA group (435 vs 201, figure 1) and reliable estimated results can still be obtained in the context of survival analysis. Fourth, as laparoscopic surgery is increasingly adopted, use of epidurals may become less for patients undergoing tumour resection for colorectal cancer. ${ }^{37}$ However, EA has been reported to be effective in improving postoperative organ function and ambulation, relieving postsurgical pain, reducing postoperative pulmonary complications and facilitating postoperative recovery. ${ }^{32-34} 38$ Based on the evidence, EA may remain a useful and beneficial treatment modality for postoperative recovery even for patients undergoing laparoscopic surgery. Finally, this study was conducted at a single medical centre and the generalisability to other places awaits more investigation.

\section{CONCLUSION}

In conclusion, there was no definite association between epidural use and cancer recurrence or all-cause mortality in patients after colon cancer resection. More evidence is 
required to confirm or refute this finding, pending the results of ongoing clinical trials.

\section{Author affiliations}

${ }^{1}$ Department of Anesthesiology, Taipei Veterans General Hospital, Taipei, Taiwan

${ }^{2}$ School of Medicine, National Yang-Ming University, Taipei, Taiwan

${ }^{3}$ Department of Anesthesiology, Shuang Ho Hospital, Taipei Medical University, New Taipei City, Taiwan

${ }^{4}$ Department of Anesthesiology, School of Medicine, College of Medicine, Taipei Medical University, Taipei, Taiwan

${ }^{5}$ Department of Anesthesiology, University of Colorado Health Sciences Center, Aurora, Colorado, United States

${ }^{6}$ Department of Surgery, Taipei Veterans General Hospital, Taipei, Taiwan ${ }^{7}$ National Yang-Ming University Hospital, Ilan, Taiwan

${ }^{8}$ Graduate Institute of Epidemiology and Preventive Medicine, National Taiwan University, Taipei, Taiwan

Contributors H-LW contributed to manuscript drafting. Y-HT contributed to data acquisition and manuscript writing. MSM helped revise the manuscript. M-YT and $\mathrm{S}$-HY helped verify the quality of the data. TH-HC contributed to study design. K-YC contributed to statistical review and manuscript revision.

Funding This work was supported by the grants from Taipei Veterans General Hospital (V104C-096), Taipei, Taiwan, R.0.C., Ministry of Science and Technology (MOST104-2314-B-075-015), Taipei, Taiwan, R.0.C., Yen Tjing Ling Medical Foundation (Cl-108-27) and Anesthesiology Research and Development Foundation (ARDF10401), Taipei, Taiwan, R.0.C.

Competing interests None declared.

Patient consent for publication Not required.

Ethics approval The study was approved by the research ethics committee of Taipei Veterans General Hospital in Taiwan (IRB-TPEVGH No. 2015-11-010CC).

Provenance and peer review Not commissioned; externally peer reviewed.

Data availability statement No data are available. Data are available on reasonable request but the approval of institutional review board will be necessary. Please contact the corresponding author for detail.

Supplemental material This content has been supplied by the author(s). It has not been vetted by BMJ Publishing Group Limited (BMJ) and may not have been peer-reviewed. Any opinions or recommendations discussed are solely those of the author(s) and are not endorsed by BMJ. BMJ disclaims all liability and responsibility arising from any reliance placed on the content. Where the content includes any translated material, BMJ does not warrant the accuracy and reliability of the translations (including but not limited to local regulations, clinical guidelines, terminology, drug names and drug dosages), and is not responsible for any error and/or omissions arising from translation and adaptation or otherwise.

Open access This is an open access article distributed in accordance with the Creative Commons Attribution Non Commercial (CC BY-NC 4.0) license, which permits others to distribute, remix, adapt, build upon this work non-commercially, and license their derivative works on different terms, provided the original work is properly cited, appropriate credit is given, any changes made indicated, and the use is non-commercial. See: http://creativecommons.org/licenses/by-nc/4.0/.

\section{ORCID iDs}

Tony Hsiu-Hsi Chen http://orcid.org/0000-0002-5799-6705

Kuang-Yi Chang http://orcid.org/0000-0002-9062-5519

\section{REFERENCES}

1 World Health Organization International agency for research on cancer. GLOBOCAN: estimated cancer incidence mortality and prevalence worldwidec in 2018, 2018. Available: http://gco.iarc.fr/ today/fact-sheets-cancers [Accessed 21 Aug 2020].

2 O'Connell MJ, Campbell ME, Goldberg RM, et al. Survival following recurrence in stage II and III colon cancer: findings from the accent data set. J Clin Oncol 2008;26:2336-41.

3 Sessler DI, Riedel B. Anesthesia and cancer recurrence: context for divergent study outcomes. Anesthesiology 2019;130:3-5.

4 Nadler JW, Quinn TD, Bennett-Guerrero E. Can anesthesiologists affect cancer outcomes? Can J Anaesth 2019;66:491-4

5 Plein LM, Rittner HL. Opioids and the immune system - friend or foe. Br J Pharmacol 2018;175:2717-25.
6 Singleton PA, Moss J. Effect of perioperative opioids on cancer recurrence: a hypothesis. Future Oncol 2010;6:1237-42.

7 Christopherson R, James KE, Tableman M, et al. Long-Term survival after colon cancer surgery: a variation associated with choice of anesthesia. Anesth Analg 2008;107:325-32.

8 Gottschalk A, Ford JG, Regelin CC, et al. Association between epidural analgesia and cancer recurrence after colorectal cancer surgery. Anesthesiology 2010;113:27-34.

9 Gupta A, Björnsson A, Fredriksson M, et al. Reduction in mortality after epidural anaesthesia and analgesia in patients undergoing rectal but not colonic cancer surgery: a retrospective analysis of data from 655 patients in central Sweden. Br J Anaesth 2011;107:164-70.

10 Cummings KC, Xu F, Cummings LC, et al. A comparison of epidural analgesia and traditional pain management effects on survival and cancer recurrence after colectomy: a population-based study. Anesthesiology 2012;116:797-806.

11 Holler JPN, Ahlbrandt J, Burkhardt E, et al. Peridural analgesia may affect long-term survival in patients with colorectal cancer after surgery (PACO-RAS-Study): an analysis of a cancer registry. Ann Surg 2013;258:989-93.

12 Vogelaar FJ, Abegg R, van der Linden JC, et al. Epidural analgesia associated with better survival in colon cancer. Int $J$ Colorectal Dis 2015;30:1103-7.

13 Myles PS, Peyton P, Silbert B, et al. Perioperative epidural analgesia for major abdominal surgery for cancer and recurrence-free survival: randomised trial. BMJ 2011;342:d1491.

14 Tai Y-H, Chang W-K, Wu H-L, et al. The effect of epidural analgesia on cancer progression in patients with stage IV colorectal cancer after primary tumor resection: a retrospective cohort study. PLoS One 2018;13:e0200893.

15 Wurster EF, Pianka F, Warschkow R, et al. Peridural analgesia does not impact survival in patients after colon cancer resection: a retrospective propensity score-adjusted analysis. Int $J$ Colorectal Dis 2019;34:1283-93.

16 Compton CC, Fielding LP, Burgart LJ, et al. Prognostic factors in colorectal cancer. College of American pathologists consensus statement 1999. Arch Pathol Lab Med 2000;124:979-94.

17 van der Sijp MPL, Bastiaannet E, Mesker WE, et al. Differences between colon and rectal cancer in complications, short-term survival and recurrences. Int J Colorectal Dis 2016;31:1683-91.

18 Tai Y-H, Wu H-L, Lin S-P, et al. Influential factors of postoperative pain trajectories in patients receiving intravenous patient-controlled analgesia: a single-centre cohort study in Taiwan. BMJ Open 2019;9:e031936.

19 Tai Y-H, Wu H-L, Chang W-K, et al. Intraoperative fentanyl consumption does not impact cancer recurrence or overall survival after curative colorectal cancer resection. Sci Rep 2017;7:10816.

$20 \mathrm{Wu}$ H-L, Tai Y-H, Lin S-P, et al. The impact of blood transfusion on recurrence and mortality following colorectal cancer resection: a propensity score analysis of 4,030 patients. Sci Rep 2018;8:13345.

21 Tai Y-H, Chu Y-H, Wu H-L, et al. High-Dose nitroglycerin administered during rewarming preserves erythrocyte deformability in cardiac surgery with cardiopulmonary bypass. Microcirculation 2020;27:e12608

22 Wu H-L, Chu Y-H, Tai Y-H, et al. Stage-Dependent angiopoietin-Tie2 and nitric oxide signaling of erythrocytes in response to surgical trauma in head and neck cancer. World J Surg Oncol 2020;18:209.

23 Thirunavukarasu P, Sukumar S, Sathaiah M, et al. C-stage in colon cancer: implications of carcinoembryonic antigen biomarker in staging, prognosis, and management. J Natl Cancer Inst 2011;103:689-97.

24 Amato A, Pescatori M. Perioperative blood transfusions for the recurrence of colorectal cancer. Cochrane Database Syst Rev 2006:CD005033.

25 Tai YH, Wu HL, Mandell MS, et al. The association of allogeneic blood transfusion and the recurrence of hepatic cancer after surgical resection. Anaesthesia 2020;75:464-71.

26 Nitsche U, Zimmermann A, Späth C, et al. Mucinous and signetring cell colorectal cancers differ from classical adenocarcinomas in tumor biology and prognosis. Ann Surg 2013;258:775-83.

27 Hogan J, Chang KH, Duff G, et al. Lymphovascular invasion: a comprehensive appraisal in colon and rectal adenocarcinoma. Dis Colon Rectum 2015;58:547-55

28 Poeschl EM, Pollheimer MJ, Kornprat P, et al. Perineural invasion: correlation with aggressive phenotype and independent prognostic variable in both colon and rectum cancer. $J$ Clin Oncol 2010;28:e358-60.

29 Edge SB, Byrd DR, Compton CC. Ajcc cancer staging manual. 7th ed. New York: Springer, 2011: 143-64. 
30 Loupakis F, Yang D, Yau L, et al. Primary tumor location as a prognostic factor in metastatic colorectal cancer. J Natl Cancer Inst 2015;107:dju427.

31 Austin PC. An introduction to propensity score methods for reducing the effects of confounding in observational studies. Multivariate Behav Res 2011;46:399-424.

32 Warschkow R, Steffen T, Lüthi A, et al. Epidural analgesia in open resection of colorectal cancer: is there a clinical benefit? A retrospective study on 1,470 patients. J Gastrointest Surg 2011;15:1386-93.

33 Hausman MS, Jewell ES, Engoren M. Regional versus general anesthesia in surgical patients with chronic obstructive pulmonary disease: does avoiding general anesthesia reduce the risk of postoperative complications? Anesth Analg 2015;120:1405-12.
34 Sessler DI, Pei L, Huang Y, et al. Recurrence of breast cancer after regional or general anaesthesia: a randomised controlled trial. Lancet 2019;394:1807-15

$35 \mathrm{Wu} \mathrm{H}-\mathrm{L}$, Tai Y-H, Chang W-K, et al. Does postoperative morphine consumption for acute surgical pain impact oncologic outcomes after colorectal cancer resection?: a retrospective cohort study. Medicine 2019;98:e15442.

36 Duineveld LAM, van Asselt KM, Bemelman WA, et al. Symptomatic and asymptomatic colon cancer recurrence: a multicenter cohort study. Ann Fam Med 2016;14:215-20.

37 Lai JH, Law WL. Laparoscopic surgery for colorectal cancer. Br Med Bull 2012;104:61-89.

38 Carli F, Kehlet H, Baldini G, et al. Evidence basis for regional anesthesia in multidisciplinary fast-track surgical care pathways. Reg Anesth Pain Med 2011;36:63-72. 